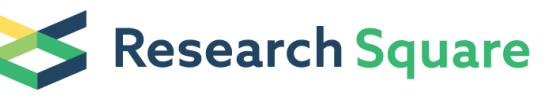

\section{The Views of People Living with Chronic Stroke and Aphasia on Their Potential Involvement as Research Partners: A Thematic Analysis}

\section{Marina Charalambous ( $\sim$ marina.charalambous@unifr.ch )}

University of Fribourg: Universite de Fribourg https://orcid.org/0000-0002-5310-3017

\section{Alexia Kountouris}

University of Sussex

\section{Phivos Phylactou}

Cyprus University of Technology: Technologiko Panepistemio Kyprou

loanna Triantafyllidou

Cyprus University of Technology: Technologiko Panepistemio Kyprou

Jean-Marie Annoni

University of Fribourg: Universite de Fribourg

Maria Kambanaros

UniSA: University of South Australia

\section{Research Article}

Keywords: stroke, patient and public involvement, people with aphasia, thematic analysis, impact, co produced research

Posted Date: January 25th, 2022

DOI: https://doi.org/10.21203/rs.3.rs-1214737/v1

License: (9) This work is licensed under a Creative Commons Attribution 4.0 International License. Read Full License 
1 The views of people living with chronic stroke and aphasia on

\section{2 their potential involvement as research partners: a thematic}

3 analysis

4 Charalambous Marina ${ }^{1,2}$, Kountouris Alexia ${ }^{3}$, Phylactou Phivos ${ }^{1}$, Triantafyllidou loanna ${ }^{1}$, Jean-Marie Annoni ${ }^{2}$, Kambanaros Maria ${ }^{4}$

${ }^{1}$ Rehabilitation Sciences Department, Cyprus University of Technology, 30 Arch. Kyprianos Str. 3036, Limassol, Cyprus;

marina.charalambous@cut.ac.cy, pp.phylactou@edu.cut.ac.cy, ia.triantafyllidou@edu.cut.ac.cy.

'Laboratory of Cognitive and Neurological Sciences, University of Fribourg, Chemin du Musée 8, CH-1700 Fribourg, Switzerland; marina.charalambous@unifr.ch https://orcid.org/0000-0002-5310-3017, jean-marie.annoni@unifr.ch https://orcid.org/0000-0002-4751-0855.

3"Solidarity Network Nicosia In Action" (NiclnAct), Multifunctional Foundation, Nicosia Municipality, Eptanisou 11, 1016, Nicosia, Cyprus;

17 Alexia.Kountouri@nicosiamunicipality.org.cy.

$18{ }^{4}$ Allied Health Unit, University of South Australia, Adelaide, East Campus (P4-

19 15D), South Australia;

20 maria.kambanaros@unisa.edu.au https://orcid.org/0000-0002-5857-9460

*Corresponding Author: marina.charalambous@unifr.ch; University of Fribourg, Faculty of Science and Medicine, Chemin du Musée 8, CH-1700 Fribourg. 


\section{The views of people living with chronic stroke and aphasia on}

48 their potential involvement as research partners: a thematic

49 analysis

50

Abstract

Background: Patient and Public Involvement (PPI) is the active partnership between researchers and patients. PPI in stroke aphasia research aims to ensure equal opportunities for informed decision-making and guarantee democratic representation in citizen control of PPI projects. Yet, little is known about the factors that hinder and/or promote the autonomous involvement of people with aphasia in stroke and aphasia PPI projects. This study aimed to explore the views and perspectives of people who live with chronic stroke, with and without aphasia, with experience in research prior to stroke, on their potential involvement as research partners.

60 Methods: The research team included a PPI partner with chronic stroke-induced aphasia. Semi-structured interviews were conducted online with people with chronic stroke $(n=8)$, four with aphasia and four without. Interviews were subject to thematic analysis.

64 Results: Inductive thematic analysis generated four themes: (1) the kinds of Restrictions that make involvement in research difficult, (2) the preferred levels and ways of Involvement during the research process, (3) the Support required for active and collaborative involvement, and (4) the Impact of their involvement and how it benefits the study's outcomes. Furthermore, people with aphasia stressed the importance of constant contextual and third-party support to sustain their active engagement within the research team.

Conclusion: People experiencing chronic stroke and aphasia are willing to be involved as PPI partners if the research team provides the necessary support. Recommendations for researchers to consider before commencing co-produced research with people with stroke and aphasia are provided.

Keywords: stroke; patient and public involvement; people with aphasia; thematic 


\section{Plain English Summary}

Patient and Public Involvement (PPI) is the active collaboration between researchers and patient groups when conducting research. PPI in aphasia research after stroke is growing in importance. Aphasia is the communication difficulty after stroke that negatively affects speaking and/or understanding, reading and/or writing. People with aphasia are usually involved in a tokenistic way in PPI studies. Tokenism is including people in the research process, who are usually at a disadvantage, by pretending that their involvement gives the appearance of equality. To avoid tokenism researchers must ensure equal opportunities for patient partners with communication challenges. This requires a supportive environment, easy access to information and opportunities for making informed choices. This study aimed to explore the views of people who live with chronic stroke and aphasia on whether they would like to be involved in PPI projects and in what manner. All participants had experience of the research process prior to the stroke event.

The research team included a person who lived with chronic aphasia after her stroke. She was named the PPI partner. Interviews were completed online with eight people with chronic stroke. Four with aphasia and four without. Interviews were analyzed and generated four themes (RISI): (1) the kinds of Restrictions patient participants face due to stroke, (2) their preferred levels of Involvement, (3) the Support they need for active and meaningful engagement and (4) their views on the Impact of PPI on research outcomes. The findings were mapped onto the International Classification of Functioning and Disability framework of the World Stroke Organization to depict how an individual's health status, limitations in activity and environmental barriers for active participation influence their engagement within the research team.

People living with chronic stroke, either with aphasia or without, are willing to be involved as patient partners. But researchers need to provide the necessary support suited to their communicative and other stroke-related needs. An aphasia inclusive PPI model will encourage meaningful research activities that make an impact, avoid research waste, rejuvenate the researcher-patient relationship dynamics, translate research outcomes into everyday life, and empower communities of people living with stroke and aphasia. 
116 Patient and Public Involvement (PPI) in stroke aphasia research is growing

117 in importance and magnitude [1,2]. PPI is the active collaboration between

118 researchers, patients and laypeople in the process of creating research practice

119 partnerships [3]. Recently, a moral line of reasoning was asserted highlighting

120 the importance of democratic representation and the empowerment of people

121 with aphasia (PWA) after stroke in research [2]. A strong argument for embracing

122 the PPI model in stroke-induced aphasia research is that it will improve the

123 quality, credibility and relevance of the study design, methods, results, and the

124 impact on research or health outcomes [4]. The importance of measuring the

125 impact of patient-orientated research is a crucial parameter of the patient

126 partnership research model, and requires continuous monitoring and evaluation

$127[5,6]$. The work of Staniszewska and colleagues on the development of the

128 GRIPP (Guidance for Reporting Involvement of Patients and the Public) [5] and

129 the revised GRIPP-2 [6], framed the significance of the impact of PPI on the

130 research itself, the patient partners involved and society at large. Funding bodies

131 have also embraced this expectation and request confirmation and transparency

132 on how patients are engaged in the preparation of the application and their

133 involvement and interaction in the research process [7]. Emphasis is also given

134 to the value of experiential knowledge provided directly from the lived

135 experiences of PWA after stroke [1]. This also has practical consequences

136 concerning authorships, guided by journal publishing policies, that demonstrate

137 authentic commitment to $\mathrm{PPI}$, and robust research practice that is ethical $[8,9]$.

138 Patient and Public Involvement projects encompass different participatory

139 approaches [10]. An approach, that includes a range of different activities

140 throughout the research cycle, can be defined in relation to 'ways of doing', 'ways 
141 of knowing", and 'ways of changing'. However, not all participatory approaches

142 achieve the same level of participation [10]. In 1969, Sherry Arnstein published

143 an influential paper entitled 'A Ladder of Citizen Participation'. In this paper,

144 Arnstein [11] described the steps involved in citizen participation metaphorically

145 as a hierarchical step ladder beginning at the bottom rungs with non-participation,

146 (i.e., 'manipulation') and moving up the ladder to 'degrees of tokenism', (i.e.,

147 'informing' and 'consultation'), and reaching the top rung of full citizen control (i.e.,

148 'partnership' and 'delegation').

149 The general expectation is that PPI in stroke-induced aphasia research

150 should underpin all stages of the research process, including how study topics

151 are identified, prioritised, co-designed, conducted, interpreted, and disseminated

152 [6]. However, McKevitt et al. [12] pointed out that since stroke survivors do not

153 perceive themselves to be an oppressed group, they have no strong desire to

154 bring about social change, which deters them from being actively involved in

155 citizen-controlled PPI research. This finding raises the question of what level or

156 levels of participation are appropriate and feasible for PWA in stroke-induced

157 aphasia PPI projects. In the study by Harrison and Palmer, [13] a thematic

158 analysis on the levels of PPI in stroke research, the authors recommend that prior

159 to the involvement of people with stroke, researchers should be proactive and

160 consider how representative of the specific projects the PPI members need to be

161 and to reduce underrepresentation, whether experiences alone are sufficient for

162 inclusion, and if PPI members need to have additional professional skills and

163 training to promote their level of involvement.

164 Even though PPI in stroke-induced aphasia research aims at reducing 165 tokenism by ensuring equal and ethical opportunities for involvement of PWA [14] 
166 the PPI concept remains problematic. It does not encompass the issues and

167 complexities of involving patients with persistant communication impairment

168 and/or other disabilities. In a recent scoping review, Charalambous and

169 colleagues [15], explored whether PWA after stroke were involved as research

170 partners in the development of Quality of Life (QOL) and aphasia-impact related

171 questionnaires given the immediate relevance of both topics to their current

172 condition. The findings revealed that PPI was mostly consultative in nature with

173 insufficient or fragmented reporting of PPI contribution levels [16]. One main

174 reason for placing PWA in a consultative role is because researchers do not have

175 explicit resources, methodologies, and frameworks on how to train, work and

176 support PWA throughout the research cycle [15]. Interpreting the findings in

177 relation to Arnstein's ladder of citizen participation suggests that researchers

178 employ tokenistic engagement by predominantly informing PWA about the

179 research topic and consulting with PWA on the relevance of the items on the pre-

180 established measures and later deciding whether to act upon their suggestions

181 or not (placation) [11].

182 For this study, which is the first part of a three-year PPI project named

183 "PAOLI: People with Aphasia and Other Lay People Involvement guidelines for

184 qualitative participatory research in aphasia research", we aim to explore and

185 understand the views and perspectives of PWA and stroke towards the demands

186 of PPI engagement, prior to their involvement with the study. The intention was

187 to recruit people with stroke and aphasia, with prior experience in research, as

188 we expected that their involvement with the research process and their living

189 stroke experience would help them to anticipate the difficulties that PWA and

190 stroke might face when involved in the PAOLI study. We also wanted to identify 
191 the kinds of support that would be needed by this group throughout the PPI process, their desired ways and level of involvement, their personal motivations, and their expectations of the impact of their engagement on the research itself,

194 themselves as individuals, and the stroke community at large [6].

195 The aim was to analyse and compare the views and opinions of PWA and

196 stroke survivors without aphasia (SSwoA) on PPI, to probe the factors that might

197 hinder and/or promote their active involvement in future PPI projects and to 198 present their perspectives on the impact of PPI on the research outcomes. The

199 findings were mapped onto the domains of the International Classification of 200 Functioning (ICF) [17], framework to determine the impact of the barriers and/or 201 facilitators to PPI on the individual's health status, activity, participation enablers and other personal and environment (contextual) factors that influence the patient's level of engagement within the research team. This approach aims to shift the focus of PPI research attention to the bi-directional and evolving linkages connecting people with stroke and aphasia to their environment, the research findings, and the impact of the research on health outcomes and clinical practice.

\section{Methods}

\section{Study Design}

This study followed a qualitative approach to investigate the perspectives

210 of people with stroke and aphasia with regards to their potential involvement as

211 research partners. Semi-structured interviews were carried out to prompt views

212 and opinions from people with stroke and aphasia. For this study, the term 'PPI 213 partner' will be used to reflect the constant commitment and engagement of a 214 person with chronic stoke-induced aphasia thought the research process. The 215 aim for collaborating with $\mathrm{AK}$ as the PPI partner, was to enhance the quality, 
216 transparency, and consistency of the evidence base for this study by involving

217 her in all stages of the thematic analysis. Although the PPI approach is secondary

218 to the thematic analysis, for the monitoring of the PPI partner engagement, we

219 followed the GRIPP-2 Short Form guidelines [6] (see appendix).

220 For the preparation, design, implementation, and analysis of the interview

221 data the consolidated criteria for reporting qualitative studies (COREQ) 32-item

222 checklist were used [18]. Previous interview protocols used in aphasia and stroke

223 research were taken into consideration for the methods employed at the

224 interviews [19]. The topic guide was developed within the research team in

225 collaboration with the PPI partner, AK, and was based on GRIPP-2 Guidelines

226 [6] and the Critical Outcomes of Research Engagement (COREs) questionnaire

$227[20]$.

$228 \quad$ Research Team

229 The research team involved a senior female speech and language

230 therapist practising in stroke-induced aphasia rehabilitation and research (MC)

231 who was the primary investigator and collected all the data, a certified speech

232 and language therapist who was the second data analyst (IT), an experimental

233 psychologist with experience in thematic analysis (PP) who was involved in

234 research methodology, data management and analysis and the PPI partner (AK).

235 AK is a 32-year-old female, with mild-moderate anomic aphasia who

236 experienced a stroke 5 years prior to the study. She holds a master's degree in

237 Research Methodologies and dropped out of her doctoral studies in Social Care

238 (University of Sussex) after her stroke event. AK is the Stroke Ambassador of the

239 Cyprus Stroke Association, and she currently works as a community social

240 worker under the auspices of the European program "Solidary Network in Action" 
241 for the Municipality of Nicosia (Cyprus). Her involvement encapsulates the 'citizen

242 control engagement level' [10], that is, from the conceptualization of the research

243 idea (to ask other people with stroke and aphasia about their opinions), in the

244 design (semi-structured interviews), for recruitment (she suggested three other

245 participants with stroke), for the analysis (she was present during the creation of

246 the thematic matrix meeting), and the dissemination of the study results (she is a

247 co-author on this paper).

248 Selection Criteria

249 Although PPI does not require prior experience and knowledge of the 250 research process, the purpose of the sampling was to recruit PWA and SSwoA, 251 with prior experience in research, that could engage in the discussion on level of 252 involvement and could anticipate the pragmatic issues around PPI while having a chronic condition. Having previous experience in PPI projects was not an inclusion criterion for this study and the interviewer was blind to such information. The inclusion criteria for this study were as follows: (1) to have experienced a stroke, (2) to be in the chronic stage of stroke (> 6 months poststroke) (3) to speak, understand, read, and write English post-stroke (4) to be socially active as confirmed from case history (5) to have at least one academic qualification, and (6) to have had previous research experience, either as a student or as a researcher. An additional inclusion criterion for PWA was to show evidence, from case history interview, of mild-moderate chronic aphasia. People with stroke and aphasia were excluded if they experienced comorbidity with additional conditions e.g., dementia, cancer, other degenerative diseases etc.

The Aphasia Severity Rating Scale (ASRS), of the Boston Diagnostic 
266 language difficulties (cut-off score 4/5). Spontaneous speech samples were 267 elicited during a 15-minute semi-structured interview that comprised of four 268 topics: the illness, previous/current occupation, family and housing, hobbies [22].

269 Aphasia severity was assessed by the interviewer using the ASRS to allow a 270 classification based on fluency and intelligibility. Scores on the ASRS range from

2710 to 5 , with 5 indicating very mild aphasic symptoms ('minimal discernible speech 272 handicap') and 0 revealing very severe non-fluent aphasia ('no usable speech or 273 auditory comprehension').

\section{Participant Recruitment}

275 Since PPI is now used in studies worldwide, geographical diversity was 276 achieved by recruiting participants from various organisations that engage in 277 stroke and aphasia research across Europe. Specifically, participants were 278 recruited from the Cyprus Stroke Association $(n=4)$, the French Association S' 279 Adapter- AVC et Aphasie $(n=1)$, the Portugal AVC Stroke Association $(n=1)$, the 280 Norwegian Stroke Association $(n=1)$ and via a snowball effect as the PPI partner, 281 AK, suggested two people with stroke from the Stroke Alliance for Europe consortium who proposed another one $(n=3)$. Participants were recruited over a 3-month period (October-December 2020).

The main researcher MC provided participants with written information prior to the interviews about the study and the participants involvement. According to the guidelines of Kagan and Kimelman [23] informed consent was received from people with aphasia after all information were provided in an accessible way to promote comprehension [24]. Consent forms (see supplementary material) were sent electronically to all participants via email and the interview process began as soon as participants had signed and returned 
291 their informed consent forms. Interviews were audio and video recorded upon

292 consent.

\section{Participants}

294 Eight people with chronic stroke, four with concomitant aphasia and four 295 without, met the inclusion criteria and gave written consent to participate. 296 Participants were aged between 27 to 70 years old, with a range of education in 297 years between 15 to 22 years. All participants had completed a research project 298 during their studies or work commitments prior to the stroke event. Specifically, a 299 participant with aphasia (J.J) was the primary investigator in several research 300 projects throughout his academic career and two SSwoA (M.M \& V.V) are

301 currently the primary investigators in research projects in their perspective fields.

302 The remaining participants were familiar with research process because of prior experience for the completion of their thesis while studying at university. All participants had right hemispheric stroke, were discharged from rehabilitation and were actively involved in the community. Participants with aphasia had received speech and language therapy intervention in the past and were currently active in aphasia communication groups. The demographic characteristics of all participants are shown in Table 1. 


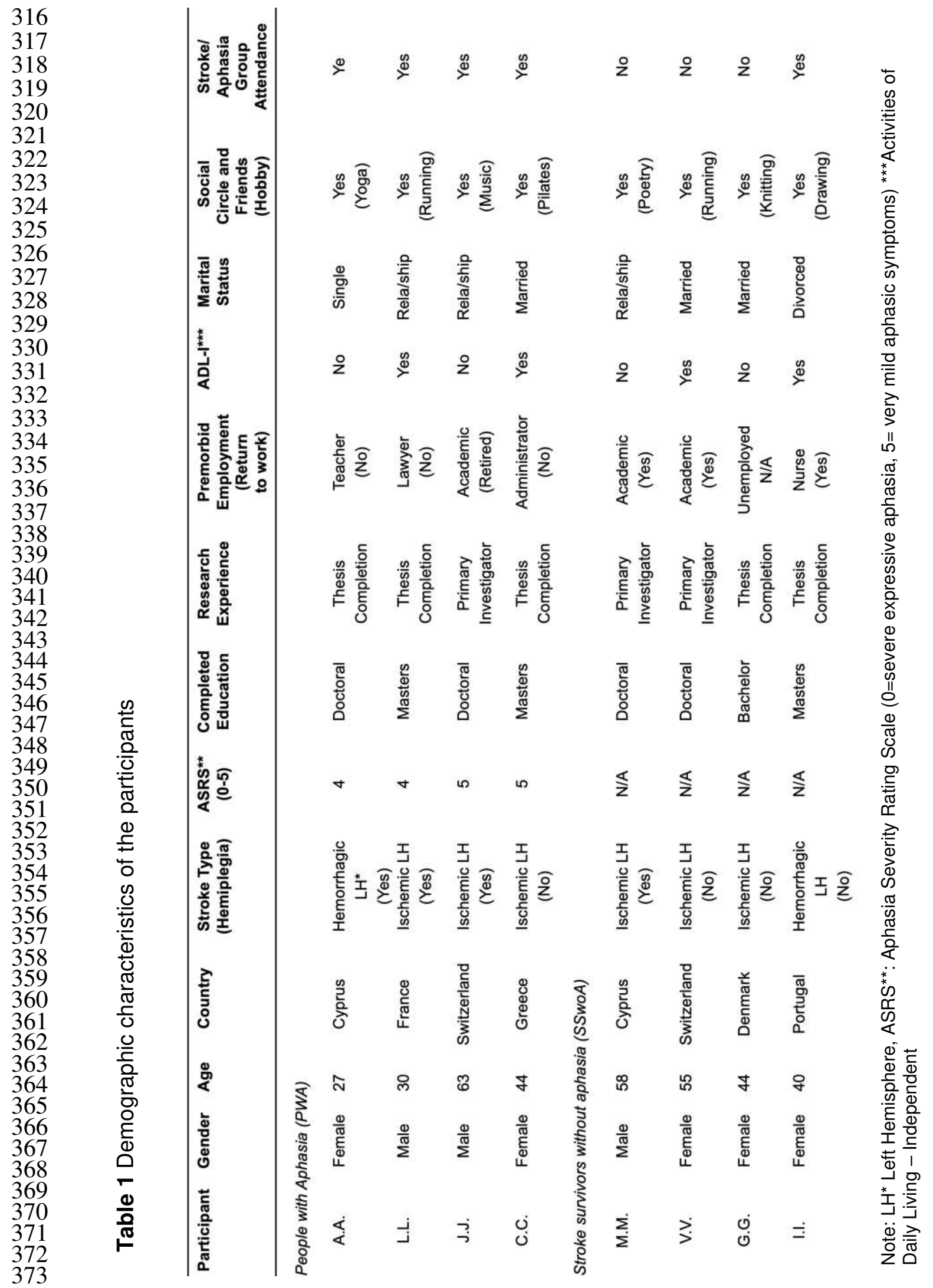

374
375

376 


\section{Pilot Interviews}

379 The topic guide was pilot tested with the PPI partner AK, in practice

380 interviews with the primary investigator MC. Due to the complexity of the subject,

381 PPI partner AK suggested to pilot again with a second person with aphasia who

382 did not participate in this study. Two questions were excluded because of

383 similarity in content and/or ambiguity.

\section{Data Collection}

The primary investigator MC conducted in-depth semi-structured interviews with all participants during a three-month period. From the start, an agreement between the interviewer and each interviewee was reached for the exact date and time at which the interviews would take place. The interviews were conducted via the online platform of Zoom. The first communication was via email. Specific instructions were provided to the interviewee to eliminate possible interruptions of the video call procedures (i.e., be in a familiar and comfortable environment, reduce environmental sound etc.). These were followed and maintained throughout the interview. MC monitored for signs of fatigue, emotional distress, and participants were encouraged to take breaks whenever required. The main researcher MC employed a flexibility in the methods of the interviews to promote maximal inclusion for participants with communication and language challenges after stroke. Both the researcher and the participants were actively involved in composing meaning via dialogue. Following the constructivist

399 paradigm as described by Guba and Lincoln [25], the personal views and subjective opinions of the participants originated from co-construction via online interaction and dialogue rather than from residual experiences [19]. 
The interviews were on average of 50 minutes duration and were

403 conducted in English as both the interviewer and the interviewees were

404 bilinguals. The interview began with a general discussion to explain the research

405 procedure, gather personal history data, and build rapport. A smooth transition

406 from pre-established open-ended questions to more specific ones was performed

407 for easier categorisation of the qualitative data and reduction of bias. Since

408 having previous experience in PPI was not compulsory for this study, broad

409 questions assisted in initiating the discussion such as: "Have you ever heard of

410 studies with Patient Involvement as researchers?", "Would you like to be involved

411 in research as a partner? and in what way?", "Why is important for you to be

412 involved as a research partner?", "In what stage of the research process would

413 you like to be involved?", "To what extent would you like to be involved?", "How

414 could the research team support you with written materials?", "How could the research team support you with discussions?", "How can you be involved in 416 dissemination?", "How do you think your involvement could influence the

417 research outcome?", "How will your involvement impact you as a person?”.

$418 \quad$ Additional supplementary questions to allow scaffolding were: "Do you 419 prefer study materials to be simplified and written in a common/plain language?”,

420 "How do you manage situations where you find it challenging to follow group 421 discussions?", "What kind of support would you need while reading complex 422 paperwork?", "Do you travel for meetings?", "What is your main challenge after 423 your stroke?', "Do you think is important for other people with stroke and aphasia 424 to know a study's outcomes?". The topic guide facilitated semi-structured 425 interviews without fixed sequencing or wording and used non-directed open 426 questions where possible, allowing for scaffolding, including binary choice 
427 alternatives and yes/no questions where necessary. Scaffolding also included 428 providing examples of what other people with stroke and aphasia had said in 429 early interviews. This structure allowed MC to provide explanatory questions if 430 needed. During the interviews, clarifications were made by the researcher when 431 needed, so that participants could understand the content of the question and 432 provide the necessary answers. The interviewer, MC, used strategies suggested 433 by the PPI partner, AK, to ensure that significant others did not speak for 434 participants with aphasia or interfere during the interview. Examples of her suggestions are as follows: "if the person is searching for a word, do not try to 436 complete their sentence or suggest a word unless they specifically ask you", "if 437 the person starts to struggle in the conversation, do not interrupt and give them 438 a chance to respond at their own pace".

439 When the interviews were completed, the recorded videos were 440 transferred to researcher IT for transcription. All data were transcribed verbatim 441 by IT and were reviewed by MC. Before initiating the thematic analysis, an online 442 meeting between the two experimental psychologists experienced in thematic 443 analysis (author PP \& colleague) and the two researchers (MC \& IT), was 444 performed to discuss the principles and methodology of the thematic analysis.

\section{Data Analysis}

446 A thematic analysis was performed to gather and analyse a large quantity

447 of information from participants into a meaningful account [26] following Braun 448 and Clarke's [27] 6-step framework:

449 Step 1 'Familiarizing yourself with the data': The recorded data were 450 viewed several times by both MC and IT (inter rater reliability). Over a period of 451 three weeks all verbal data were transcribed into scripts and $M C$ revised the 
452 transcripts again while watching each video separately (test retest). Later, all 453 transcripts were again reviewed by $\mathrm{MC}$ and IT independently (intra evaluator 454 coherence) and the final version of the transcripts was drafted. Non-verbal behaviours and cues (for example voice tone and volume, pauses, gestures, 456 facial expression) pertinent to the research questions were documented in a 457 separate file. All identifiable information was removed at transcription and participants were assigned random initials.

Step 2 'Generating initial codes': IT and MC proceeded with the initial generation of the raw codes. Codes are defined as a feature of the data that refer to "the most basic segment, or element, of the raw data or information that can

462 be assessed in a meaningful way regarding the phenomenon" [p.63: 27] e.g., 463 'wheelchair', 'communication buddy', 'fatigue'. After initial code generation, the 464 two researchers MC and IT had a face-to-face five-hour meeting with the experimental psychologist experienced in thematic analysis (author PP) and the PPI partner AK to initiate and monitor Steps 3, 4 and 5.

Step 3 'Searching for themes': all codes with similar meanings were represented graphically in categories as discussed by each group. After codes were grouped into categories, sub-themes and finally themes emerged. A theme is defined as a word or a phrase that describes and summarizes the core point of a consistent and coherent idea patterned in the data [27] e.g., Restrictions. In the

472 present study themes focused on the participants' implicit ideas, perceptions, and 473 views on their potential involvement in PPI research.

Step 4 'Reviewing themes': all initial themes were identified, examined, and differentiated to observe whether there was a connection between the data within the themes, while the differences between the topics were apparent to all 
477 four members of the research team. Themes were refined as part of an iterative 478 process and consensus was reached between the four researchers (MC, IT, PP 479 and AK). The final themes were then organized into a matrix, following a bottom480 up approach, to generate a thematic map that represented the important 481 information relayed in relation to the research questions.

$482 \quad$ Step 5 'Defining and naming themes': the selection of the names was 483 dependent on the content and meaning of each theme. Again, all researchers 484 concluded on names after consensus was reached. Finally, the thematic matrix 485 with key themes, subthemes, and categories, was completed. When data 486 analysis was completed, author MC proceeded with step (6) 'Write-up'. See 487 Figure 1 for the flowchart of the thematic analysis process. 


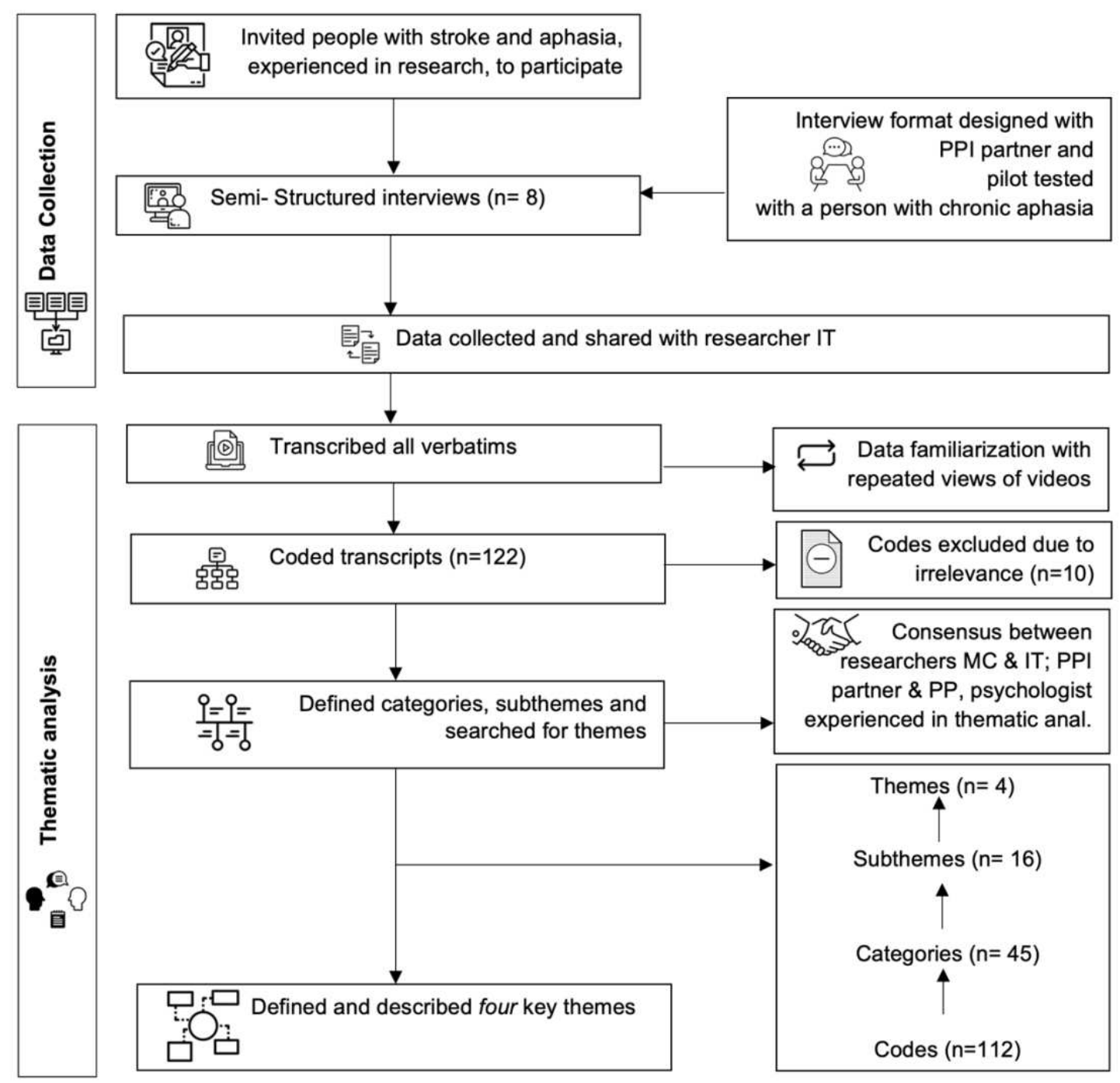

Fig. 1 Flowchart of the thematic analysis processes

Rigor

493 in research, it is vital that it is completed in a rigorous methodological manner to

494 create meaningful results [28]. For this study the following strategies were

495 employed to enhance the fidelity of the data: (1) pilot interviews were conducted

496 which were evaluated within the research team, and ensured that the selected

497 questions were accessible to PWA and lacked ambiguity [29, 30], (2) two online

498 meetings took place to monitor the methods and procedures of the thematic

499 analysis, (3) all transcripts were reviewed multiple times independently (test 
500 retest and for intra rater agreement) and (4) a face-to-face meeting took place to

501 monitor the data analysis and interpretation.

Results and IT shortlisted the codes to 112. During the analysis, the bottom - up approach was used, starting from codes $(n=112)$ to categories $(n=45)$, from categories to subthemes $(n=16)$, and finally to key themes $(n=4)$ to result in a thematic matrix (see Figure 2).

$512 \quad$ Living with stroke and aphasia

513 Improve stroke survivor's QOL

514 Raise Awareness

515 Improve Outcome and Impact

516 Differentiate Outcome

517 Generate Real Life Results

518 Review Researcher-

519 Passive subject*

Technological Support Communication via email Computer assistance* Speech recognition software* Online meetings ${ }^{\star}$

Contextual Support

Reading quietly*

Translation online*

Simplified text

Bullet points*

Aphasia friendly format

Third Party Support

Communication partners*

Family members*

Between people with aphasia*

pact

\section{IMPACT}
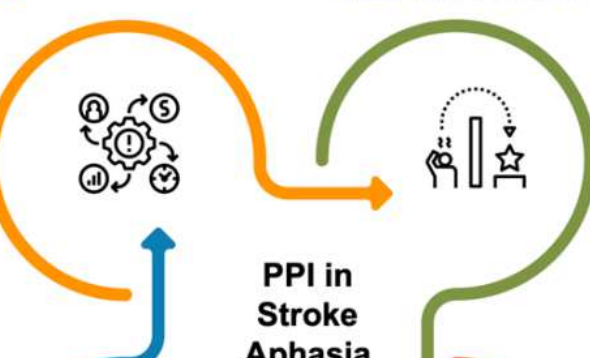

RESTRICTIONS

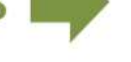

Word finding difficulties

Stuttering

Swallowing difficulties Commuting

Restrictions in driving* Travelling limitations Other Restrictions Time Health Mobility

Priorities Quality of life ${ }^{*}$ Walk, Physiotherapy Intensity of Involvement Involvement in all stages During participant recruitment*

Dissemination events* Individualism Personal experience* Tailor made research* Motivation Move forward* Joint publication* New challenge ${ }^{*}$ Get in touch with research* Make new connections*

Fig. 2 The thematic matrix with themes $(n=4)$, subthemes $(n=16)$ and categories $(n=45)$. ${ }^{*}$ Discussed only by PWA

The four key themes were discussed by all participants. However, six

538 subthemes $(n=6)$ were discussed only by PWA: (1) 'Individualism' and (2)

539 'Motivation' from the Involvement theme, (3) 'Contextual Support' and (4) 'Third 
540 Party Support' from Support theme, (5) 'Contribution to Dissemination' and (6)

541 'Review Researcher - Participant Relationship' from the Impact theme. Both

542 groups mutually discussed 10 subthemes, with no subthemes discussed by the

543 SSwoA group exclusively (see Figure 3).

544

545

546

547

548

549

550

551

552

553

554

555

556

557

558

559

560

561

For each group, individual categories have been represented in a section

562 of the Venn Diagram. The categories discussed by each group individually and

563 those discussed in common that resulted from the thematic analysis (see Figure

$5644)$.

565

566

Fig. 3 The subthemes $(n=16)$ as discussed by both groups and by the PWA group only.

1. Communication

2. Social participation

3. Commuting

4. Priorities

5. Other restrictions

6. Intensity of

involvement

7. Technological support

8. Influence \& empower

stroke community

9. Raise awareness

Improve outcome

and impact

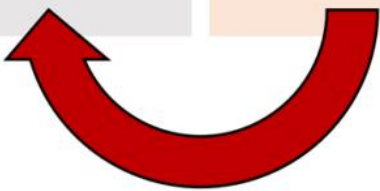

2. Motivation

3. Contextual support

4. Third-party support

Contribution to

6. Review researcherpatient relationship

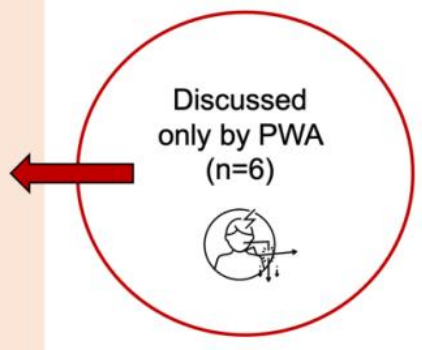




\section{The four themes}

Fig. 4 A Venn diagram reporting the categories discussed by PWA and SSwoA separately and together

- Poor relationships

- Social isolation

- Writing difficulties

- Slow reading

- Word finding difficulties

- Time management

- Health

- Involvement all stages

- Email communication

- Simplified text

- Accessible formats

- Living well with stroke

- Improve QOL

- Lack of education

- Differentiate outocme

- Generate real life results

583 Restrictions, Involvement, Support, and Impact. Restrictions describes

584 participants' opinions about the difficulties they face after stroke that might

585 prohibit their active engagement in the research process. Involvement portrays

586 the ways in which participants would like to be included as members in the

587 research team, whereas Support reports the approaches/methods that

588 participants suggested can facilitate their active involvement and self-

589 management throughout the research process. Finally, Impact reflects

590 participants views on how they consider their involvement would benefit the

591 research itself, but also the stroke and aphasia community. 
It is important to mention that most participants (except I.I) responded

593 negatively to the first question of the interview "Have you heard about studies

594 with patient involvement as researchers?". Most participants were surprised by

595 the opportunity of such a methodological approach in health research. This

596 observation is of high significance to researchers as it stresses the importance of

597 raising awareness around PPI prior to patient partner recruitment. Even though

598 most of the participants had some experience with research, either due to their

599 professional occupations (researchers) and/or academic studies, they all

600 requested a brief explanation from the primary investigator, $\mathrm{MC}$, on the

601 characterization of $\mathrm{PPI}$ and how it is reported in recent studies. Once MC

602 provided examples of PPI in recent cancer and dementia studies [31, 9],

603 participants began to be engaged with the interview topic. Both groups (PWA \&

604 SSwoA) discussed the importance of sharing personal 'lived' experiences post

605 stroke with the rest of the research team to promote 'realistic' and 'pragmatic' 606 research $[32,33]$.

607

608 Theme 1 Restrictions

609 The Restrictions theme includes participants' opinions on the constrains

610 and barriers they might face as PPI members of a research team, due to either

611 their difficulties with communication and mobility, or other stroke-related health

612 issues (see Table 2).

613

614

615

616

617 
618 Table 2 Theme 1 results on 'Restrictions' with subthemes, categories, and examples

\begin{tabular}{ll}
\hline Theme & Description \\
\hline Restrictions & The kind of difficulties that make engagement in research challenging
\end{tabular}

$\begin{array}{ll}\text { Subthemes } & \text { Categories } \\ \text { Social } & \text { Poor Relationships } \\ \text { Participation } & (3) \\ \text { (3) } & \text { Social Isolation (2) } \\ & \\ \text { Difficulties } & \text { Writing Difficulties } \\ (6) & (5) \\ & \text { Slow Reading (3) } \\ & \text { World Finding } \\ & \text { Difficulties (3) } \\ & \text { Stuttering (1) } \\ & \text { Swallowing } \\ & \text { difficulties (1) }\end{array}$

\section{Participant testimonies}

[I.I] "Like...And there were many people that tell me things like.... that I did not call you because I thought you could not speak..."

[L.L] "For example, when I write email, maybe it's a simple email 2 sentences or 5 sentences. And then I have to reread, reread, reread. And I have [short pause] write down the few words. The one sentence, if it's short sentences [short pause] long sentences [...] I can write it but i i can i need to reread, reread, reread, reread, and I send my documents also my the mother of my girlfriend. And she checked the words the sentence. I guess I I have problem... I know, I know, don't have problems with sin... syntax. But when I write long sentence."

[A.A] "I having difficulty in participating in the group when writing something [...] Yes yes.. eehh okay and if it's a difficult, for example article, I can read them but I will need much more time".

[L.L] " [Discussing about group engagement] there is two problems. My aphasia and also my [short pause] I can say it in French [short pause] (Participant raises his hemiplegic hand to the screen)".

[J.J] "[..] but you have just to know, that I'm not very good with typing. So, for me to return an email, maybe takes a day or two".

[V.V] "When in a group you and you can't remember the name of this also, or the name of this intellectual or precise things like this and its challenging...".

Commuting Restrictions in (2)

Driving (1) Traveling Limitations (2)

Time management (6)

restrictions

(6)
[M.M] “I haven't travelled yet, and I don't know if I would ever can do it [long pause] I don't know, it's difficult, I need support."

[C.C] "I cannot take the car...nor the bus. It takes time [long pause] tired. Maybe do meetings online"'. [A.A] "I need someone to take me to places. with aphasia is difficult to drive [short pause] home visit is better for research".

[L.L] "And I don't think that I will be a partner [short pause] fully, fully, because my work and my work my, my [short pause] time."

[M.M] "Time is always an issue. You see I have my lectures, research and family also. Maybe not full-time research partner".

$[V . V]$ "I think what is very difficult to me to be in group. I had the stroke when I was 40 and my kids were kids. And so, when I came back I was lucky that I had very light consequences, but I have to manage somehow 
my real state of fatigue. It's difficult to attend long meetings... it makes me more tired". because of stroke discussed equally by PWA and SSwoA. Specifically, SSwoA referred to acquired stuttering, difficulties with swallowing and writing challenges due to hemiplegia whereas PWA were focusing on the impact of aphasia. PWA explained their current communication difficulties across language modalities, and how their poor communication skills led to high risk of social isolation, and poorer social relationships and therefore low engagement with the PPI team. Also, PWA supported the view that their communication and language difficulties might pose a barrier to their contribution as research partners. reluctance to travel to other cities or countries for research purposes mainly

632 because of low confidence in travelling alone or unattended. Likewise, time was 633 an issue discussed extensively as stroke survivors felt unable to devote

634 themselves entirely to research, due to personal and professional obligations.

635 Additional limitations regarding their health were examined by both groups. 636 Specifically, participants argued how hemiplegia, aphasia, depression, and 637 fatigue, in combination or solely, could challenge their capacity to partake in the 638 research team.

\section{Theme 2 Involvement}

The second theme Involvement emerged from the views of all PWA and

641 two SSwoA on the reasons and the ways they would like to be included in the 642 research team as partners (see Table 3). 
644 Table 3 Theme 2 results on Involvement with subthemes, categories, and examples

\begin{tabular}{ll}
\hline Theme & Description \\
\hline Involvement & $\begin{array}{l}\text { The preferred levels and ways of involvement during the research } \\
\text { process }\end{array}$
\end{tabular}

\section{Subthemes Categories}

Priorities (2) Quality of life (1)

Walk (2)

Physiotherapy (1)

Intensity of Involvement in all involvement stages (4)

(4)

Individualism

(4)

Motivation

(4)
During participant recruitment (3) Dissemination events (4)

Personal Experience (3) Tailor made research (3)
Participant testimonies

[A.A] "Life with a stroke is difficult, and with aphasia [long pause] I want better quality in my life [long pause] let people know."

[A.A] "I want In the interviews, groups in research, do questionnaires, things like that.. I can also invite $C$.. can also join the team".

[G.G] "From beginning... until the end (Participant nods head for confirmation)".

[I.I] "I can tell people from my group to join the team".

[J.J] "I can send to my French aphasia group... your research the, the questionnaires also, the results".

[A.A] "It will be helpful for the groups, aphasia groups, and to support the aphasia, aphasia group. For example, [short pause] let's say you have a question, and they (the researchers) will tell their opinion and us our experience [short pause] they will improve the research question" [...] Questions will be real, because people with the aphasia will be asking the question, and they know why they are asking".

[J.J] Involved, that can bring something to the people with aphasia. It... ammm ... making it easier for them to communicate? The... Yeah, sort of... l'd like to be involved...So that I can help them with whatever the problem is... a bit communicate, a bit the family, a bit at the workplace, whatever it maybe hopes to contribute a little bit to".

[I.I] I think in some in some researchers, they do that (the PPI) and that's fantastic. Because it's completely different to understand the things or the person's point of view that knows exactly what they feel and also for the persons that are answering. If they feel understood, they open more. So some studies... some studies in health area do that, but not many. Not many that I know not that I'm aware".

[C.C] "Questions will be real because people with the aphasia will be asking the question [short pause] and they know why they are asking [short pause] and they know that everybody else with aphasia will understand....".

[A.A] I have one stroke in my life, and I would like to move forward. But myself...I will move forward...I would like to be more focused in stroke and aphasia research."[...] "Experience. You will have more 
Get in touch with research (3)

Make new

connections (4)
646

647

648

650

651

652

653

654

656

658

660

661

662

663 experiences. Compared with the ones who are not in these things."

[C.C] "It is important ...eem ...yeah. I mean it's... yeah I'm okay... I'm... I think so. It is actually challenging to be in research".

[L.L] [...] "And also, I would like to be more in research for stroke and aphasia. I don't know why, but [long pause]" (Participant raises both shoulders up)[...] "Because I was in Erasmus, I have friends all over Europe and I would, I would like to be more in touch with the research. I would like to be part of a European team" [...] I would like to [short pause] go to see it and I would like to make connections for the aphasia groups."

Note: In parenthesis is the number of participants that reported on each subtheme and subcategory

Under the Involvement theme participants argued that their intervention within the research team would be beneficial to guide the research questions towards the realistic needs of stroke and aphasia communities. Specifically, PWA discussed individualism and how through their real-life experiences, this will facilitate the formulation of specific questions and tailor-made research. With regards to the intensity of their involvement, participants stated that they wished to be involved in all stages of the research, from recruitment to dissemination since they have access to stroke and aphasia support groups. Finally, PWA stressed the importance of having a personal motivation to move forward, contribute to a research publication, experience a new challenge, get back in touch with research, and expand their social circle by making new connections with other people with stroke and aphasia.

\section{Theme 3 Support}

The third theme Support which involves opinions and views about the support mechanisms that will promote meaningful PPI within the research team was discussed by all PWA and one stroke survivor without aphasia (see Table 4). 
665 Table 4 Theme 3 results on Support with subthemes, categories, and examples

\begin{tabular}{|c|c|c|}
\hline Theme & \multirow{2}{*}{\multicolumn{2}{|c|}{$\begin{array}{l}\text { Description } \\
\text { The support required for active and collaborative involvement }\end{array}$}} \\
\hline Support & & \\
\hline Subthemes & Categories & Participant testimonies \\
\hline $\begin{array}{l}\text { Technological } \\
\text { Support (3) }\end{array}$ & $\begin{array}{l}\text { Online meetings } \\
(2) \\
\text { Communication via } \\
\text { email (3) } \\
\text { Computer } \\
\text { assistance (3) } \\
\text { Speech recognition } \\
\text { software (1) }\end{array}$ & $\begin{array}{l}\text { [G.G] "For example if we are deciding that we are } \\
\text { going to do a questionnaire, do it online. Yes? } \\
\text { Because it's different countries is difficult.... So we are } \\
\text { not travel and we cannot meet. So we're doing online } \\
\text { meetings." } \\
\text { [C.C] "We can communicate with email. So I have time } \\
\text { to respond, think and write." } \\
\text { [L.L] "It's difficult to write.... I can write with my left } \\
\text { hand. And, indeed. But it's more difficult. But I can } \\
\text { write by computer". } \\
\text { [J.J] "Because of the D.D program that that I have. } \\
\text { With which, by the way, I used to do all the lectures } \\
\text { and so on [short pause]. D.D is a speech recognition } \\
\text { program. And it's a bilingual program. And so, it's } \\
\text { always with English, English, German, English, } \\
\text { French, English, Greek, and so on. And I dictate to the } \\
\text { program [...] the computer then types the text into the } \\
\text { file". }\end{array}$ \\
\hline
\end{tabular}

Contextual Reading quietly (1)

Support (3) Simplified text (2)

Bullet points (1)

Accessible format

(2)

Translate online (1)
Third party

Support (4)
Communication

partner (2)

Family member (2)

Between PWA (1)
[A.A] "I can read it slowly slowly, I mean quietly, and I use a highlighter and if I find difficulties, my mum or dad help me out to understand them or my siblings".

[J.J] "Yes, short sentences would be easier for me."

[L.L] "I can read. I can read without the images, the pictures. I can have a pattern that I would... that someone can help. I would like to...It's also difficult for me to understand in English. For me it's more or less bullet points".

[C.C] [...]"Pictures and simple words is help in the text."

[A.A] "Emm when a find a word is unknown, I will search for it and I find its translation in Greek or English, online with a computer".

[C.C] "I would like to be with someone with the English very good to help me with the team [...] like the student in the aphasia group [short pause] to help with the group things to do in the team".

[L.L] "I can write it but I I can I need to reread, reread, reread, reread, and I send my documents to my father, my girlfriend, my sister [short pause] to examine"

[A.A] "People with aphasia can help other people with aphasia to understand and speak in the team". 
Participants discussed the need for constant Support to regularly attend 668 face-to-face meetings due to their persisting difficulties with mobility, 669 transportation, and communication. To reduce travel expectations, they 670 suggested online meetings and communication via email. They also expressed 671 that further technological support would be needed to promote functional 672 communication such as the use of applications for direct messaging and 673 communication related software. Moreover, PWA revealed the ways in which 674 they can be facilitated to understand the research process with written material 675 such as simplified text, bullet points, and the addition of pictures in line with the 676 text. Additionally, PWA argued the need for constant third-party support from a 677 communication partner, a family member or between PWA.

\section{$678 \quad$ Theme 4 Impact} Finally, the fourth theme Impact was discussed by all participants. This 680 theme included participants views regarding the impact they consider their 681 involvement would have on the research outcome and for the stroke and aphasia 682 community (see Table 5).

Table 5 Theme 4 results on Impact with subthemes, categories, and examples

\begin{tabular}{|c|c|c|}
\hline Theme & \multirow{2}{*}{\multicolumn{2}{|c|}{$\begin{array}{l}\text { Description } \\
\text { The Impact of their involvement and who it benefits research }\end{array}$}} \\
\hline Impact & & \\
\hline Subthemes & Categories & Participant testimonies \\
\hline $\begin{array}{l}\text { Contribution } \\
\text { to } \\
\text { dissemination } \\
\text { (3) }\end{array}$ & $\begin{array}{l}\text { Promote real life } \\
\text { priorities (3) } \\
\text { Spread the word } \\
\text { via support } \\
\text { organizations (3) }\end{array}$ & $\begin{array}{l}\text { [M.M] "Involved, that can bring something to the people } \\
\text { with aphasia. It [short pause] making it easier for them } \\
\text { to communicate. Then yeah, sort of I'd like to be } \\
\text { involved [short pause] so that I can help them with } \\
\text { whatever the problem is a bit communicate, a bit the } \\
\text { family, a bit at the workplace, whatever it maybe hopes } \\
\text { to contribute a little bit to." }\end{array}$ \\
\hline & & $\begin{array}{l}\text { [L.L] 'Yeah yeah. Communications. But I would like to } \\
\text { say it's difficult for me and us in France. If you don't }\end{array}$ \\
\hline
\end{tabular}


Influence and

Empowering

Stroke

Community

(4)

Raise

Awareness
Improve QOL of people with stroke and aphasia (3) Living with stroke and aphasia (3)
Improve

Outcome and Impact (5)
Lack of education (2)

Differentiate Outcome (4) Generate real life results (4)
Review

Researcher

Participant

Relationship

(1) speak English [short pause]" [...] "I can send to my French aphasia group [long pause] to tell them." $[J . J]$ if you invite me in conference or in workshop, I can either European one or French one, to explain the study".

[J.J] Improve the life of those living with the aphasia...that's the most important thing .. the outcome is so important for the people who have strokes and so on".

[I.I] "I feel... I'm happy to do anything that can help people to understand the difficulties that persons with strokes or aphasia have, it's very important that other persons understand the difficulties and understand a little bit more about aphasia, so that people would noy want to be so isolated."

[I.I] "Even health care professionals don't understand" [...] "That [short pause] worries me very much is how much [short pause] lack of information professional health have [short pause] because I was I was Intensive Care Nurse. I was in the top I should know everything, and I didn't [long pause]."

[V.V] "I think aphasia is one of the hardest difficulties that people can have. And it's also one of the difficulties that isolate more the stroke survivors, especially the young ones. And, and I've been trying to call attention in the hospital about that, because...they are quiet, and they stay at home. And I think is one of the hardest sequels that persons can have. Because then they cannot express. So, it's really hard. So, it's... I'm very happy if we are doing something in that area."

[J.J] "Real results from life... Yeah, that's, that's for sure... that's for sure. And I really hope that people are going to read it afterwards. Understand and change things...".

[A.A] "Results will be different...people will ask the questions, so real outcomes. Will have more real outcomes".

[C.C] "My part [short pause] it will have more experiences and more quality than...Yes research will have different and real result [short pause] better quality after."

[C.C] "So I remember... because I was doing my myself for another research. I knew very little [short pause] and I have to give my consent that of course my data could be used for research material and just [long pause] I felt that I was [long pause] I was in an object in a study if you wish, so I didn't feel that I was the agent in that [short pause]. I mean it was fine with me but, this is how I conceived the relationship between researcher and the patient. The patient is somehow by definition passive, I guess." 
Under Impact participants argued that their contribution to the research process will positively affect the Dissemination of the results to stroke communities due to their role as patient representatives. However, they stated that it might be challenging to disseminate research results to local stroke and aphasia societies since most research is written in English, a non-dominant

691 language in their countries. Likewise, participants discussed the Impact of such 692 an inclusive PPI partnership research model on the stroke and aphasia community in terms of positive influence and empowerment. They also debated

694 the lack of education around stroke and aphasia, the wish to raise public awareness and for health professionals to promote successful living with stroke and aphasia. To improve outcome and research impact participants discussed 697 that their involvement would generate real life results due to their original contribution. Lastly, a participant with aphasia emphasised the passive role of patients as subjects in research studies and discussed a must-needed change in the power dynamics of the patient-researcher relationship with the addition of patient partners in research teams.

\section{Discussion}

This study, which to our knowledge is the first attempt to investigate the views and perspectives of people with chronic stroke, with and without aphasia, around potential involvement in PPI projects. All eight participants were experienced in research prior to their stroke, although this is not mandatory for participation in PPI studies. The anticipated challenges of active PPI in stroke and aphasia research and the support mechanisms that would promote the active, collaborative, and independent involvement of people with communication 
710 and/or physical and sensory impairments after stroke at the level of 'citizen-

711 control' were reported. Finally, the results magnify the research impact of PPI for

712 end users, the study itself as well as the stroke and aphasia community at large.

\section{Similarities between PWA and SSwoA}

The findings of this study revealed that both groups contributed similar responses to the research topic guide, with little variation from PWA. Although none of the participants were familiar with the term PPI or had any previous experience, they all stated an interest in becoming involved in PPI studies under

718 certain conditions. Both groups acknowledged the importance of the PPI

719 partnership in stroke and aphasia studies as means of generating meaningful results. The most identified themes included information on how restrictions in mobility, barriers to transportation, communication difficulties and other health limitations are factors that hinder the frequency and intensity of their involvement. Participants from both groups stressed the importance of a robust support system within the research team governance, to encourage co-produced PPI research at 725 the level of citizen-control. by the participants on how they could be effectively supported by the researchers

728 within the research team in managing reading, writing and group discussions.

729 Both groups also discussed the issues related to the profound symptoms of 730 stroke under Restrictions and how motor and communication difficulties pose 731 barriers to their motivation for synergistic engagement within the research team

$732[13,34,35]$. Restrictions in commuting and time-management factors were also

733 discussed. This was also true in the Harrison and Palmer [13] study where 
734 participants mentioned that distance and restrictions in travelling due to motor and access difficulties, restricted the frequency and intensity of their physical presence and hence overall involvement in the meetings of the research team.

737 Time restrictions due to personal and professional engagements were similarly 738 evident in the Harrison and Palmer [13] study where participants stated that 739 during the active period of the study, they did not have enough spare time to get 740 sufficiently involved. Thus, it is important that researchers explain to patient 741 participants, before their involvement about how they will be safely transported to 742 the research venue on every occasion and how they will be financially supported 743 to use personal vehicles or transportation [36, 37]. Also, to eliminate the 'burden' 744 of being involved in time consuming studies the research team should determine 745 mutually agreeable timetables and research agenda timelines before the commencement of the research.

Similarly, the issues around Involvement discussed by both groups,

748 highlighted how their acquired communication difficulties, beyond aphasia, 749 impacted their social interaction skills which can impose on the collaboration 750 process within the research team. Such difficulties can be monitored by encouraging PWA to attend weekly stroke and aphasia support groups that

752 promote social connectedness and improvement of communication skills [38].

753 Different methodological approaches used in support groups such as learning 754 events, personal stories, conversation strategies, and patient narratives can be 755 used to foster communication skills practice and active engagement [39, 1].

756 Finally, prior to the recruitment of patient partners, researchers should proceed

757 with a one-on-one meeting with each potential patient partner to build rapport, 758 briefly explain their commitments and obtain a detailed medical history. Such an 
approach would enable researchers to be proactive and create an inclusive and

760 positive research environment for PPI.

\section{Differences between PWA and SSwoA}

Differences between the two groups emerged during a deeper analysis of the data. They highlighted individualism, the uniqueness of each person with stroke-induced aphasia, and the need to share personal perspectives and experiences about the impact of the loss of communication within the research team, as these are topics often ignored by researchers [40]. The results are in line with the evidence from other clinical populations that have communication impairment and difficulties with access to research involvement, for example, people with complex speech and motor disorders [41]. Discussion on motivation also emerged from the PWA group. PWA were able to identify several types of motivational factors to promote their involvement as follows:

- establish new links to the stroke society by making new connections with other people with stroke and aphasia

- extend on their previous research work

- get in touch again with known past researchers

- participate in a joint research publication

- acquire a deeper understanding of their condition

- move forward in terms of personal development by taking on the challenge of collaboration in PPI projects.

We also report participants' testimonies that reveal socially motivated behaviour to engage in PPI studies, to raise stroke and aphasia awareness, not only in the stroke community but also in the public and the medical society. 
Participants with aphasia also stressed the necessity for constant thirdparty support, i.e., communication partners and engagement from various facilitators to manage verbal and written content within research consortiums.

786 Since all participants with aphasia were actively engaged in aphasia communication support groups, they could anticipate the value of communication partners as part of the research team. The recruitment of communication partners and facilitators such as healthcare students and trained volunteers $[42,43,44]$ is warranted to avoid the risk of being tokenistic within the team. It is suggested that potential patient partners with aphasia be recruited from aphasia communication groups, as they are familiar with communication partner practices, are acquainted with group interactions and are more likely to express their individual needs and 794 views during the research process. under technological support to enhance the conventional methods of engagement such as speech recognition software, technological aids etc. They suggested information on contextual support such as use of simplified text, pictures, and infographics in written material which supports previous research on accessible material for people with aphasia [24]. Additional training sessions on accessible research vocabulary, design, and methodology before the initiation

802 of the study [45] are recommended. Any such facilitators or compensation 803 strategies should be defined, prepared, and monitored by researchers before 804 patient groups become involved with the research process. Finally, PWA expressed the wish to be part of the dissemination process that could be realised

806 via access to their stroke and aphasia support groups. They purported to be in a 807 better position to communicate research findings and terminology in a less 
808 complicated manner that peers with aphasia and communication challenges

809 would appreciate. The importance of contextual and third-party support was only

810 stressed by PWA as a prerequisite for active engagement (citizen- control level

811 of Arnstein's ladder). Finally, a critical key point discussed by the PWA group was

812 the participant-researcher relationship. This emerged from a participant's

813 negative experience of being a passive subject in a study following her stroke.

814 This area puts into question the traditional role boundaries, raises multiple ethical

815 dilemmas and methodological challenges in qualitative and experimental

816 research for people with communication impairments [2] and stresses the

817 important topic of participation and power equalization in the patient-researcher

818 relationship [32].

819 The factors that hinder or promote the active involvement of PWA and

820 SSwoA

821 The factors that hinder or promote the active involvement of PWA and

822 SSwoA have been identified and are presented in tables 6 and 7. Specifically,

823 the factors that might hinder active engagement in potential PPI studies are

824 mostly related to communication and commuting difficulties, poor social

825 participation, and stroke related health issues (see Table 6).

826 Table 6 Barriers to active engagement.

\begin{tabular}{ll}
\hline Barriers & Categories \\
\hline Communication Difficulties & Writing Difficulties \\
& Slow Reading \\
Word Finding Difficulties & Stuttering \\
& Swallowing Difficulties \\
Commuting & Travelling Limitations \\
& Restrictions in Driving \\
Social Participation & Poor Relationships \\
& Social Isolation \\
& \\
Health Issues & Fatigue \\
& Depression
\end{tabular}


Mobility

Cognitive Impairments

Aphasia

Furthermore, the following facilitators were raised by all participants, such

828 as technological, contextual and third-party support and motivation that might

829 promote their engagement in citizen control PPI projects (see Table7).

830 Table 7 Facilitators that enable active engagement

\begin{tabular}{ll}
\hline Facilitators & Categories \\
\hline Technological Support & Communication via Email \\
& Computer Assistance \\
Speech Recognition Software & Online meetings \\
Contextual Support & Quiet Reading \\
& Translation Online \\
& Simplified Text \\
& Bullet Points \\
& Aphasia Friendly Format \\
Third-party support & Communication Partners \\
& Family Members \\
& Between PWA \\
Motivation & Move Forward \\
& Joint Publication \\
& New Challenge \\
& Get in touch with research \\
& Make New Connections
\end{tabular}

831 The Impact of PPI

832 To conclude the discussion of the results, a second middle-ground

833 approach was used based on the mapping of the results onto the ICF as a

834 conceptual framework [17]. As predominantly a taxonomic scheme, the ICF

835 provides a means of classifying variables associated with human functioning and

836 disablement (body function and structure, activity, and participation) in context

837 (environmental and personal factors). The mapping of the results to the ICF

838 suggests a need to focus PPI research attention on the bi-directional and evolving

839 linkages between people with stroke and aphasia to the environment, the

840 research and the overall impact on the research process and outcomes [46]. This

841 incorporates the four key themes, and all subthemes including the strategies that 
842 SSwoA and PWA suggest could implemented by the researchers for constant

Fig. 5 The themes $(n=4)$ and subthemes $(n=16)$ mapped onto the ICF

\begin{tabular}{|c|}
\hline $\begin{array}{l}\text { Environmental Factors } \\
\text { Commuting } \\
\text { - Travelling Limitations } \\
\text { - Restrictions in Driving } \\
\text { Social Participation } \\
\text { : Poor Relationships } \\
\text { - Social Isolation } \\
\text { Other Restrictions } \\
\text { - Time }\end{array}$ \\
\hline
\end{tabular}

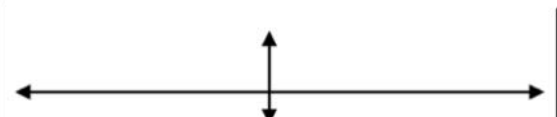

Contextual factors Communication Difficulties - Writing Difficulties Body Functions and Structures Health

- Fatigue

- Depression

- Mobility

- Cognitive

- Aphasia

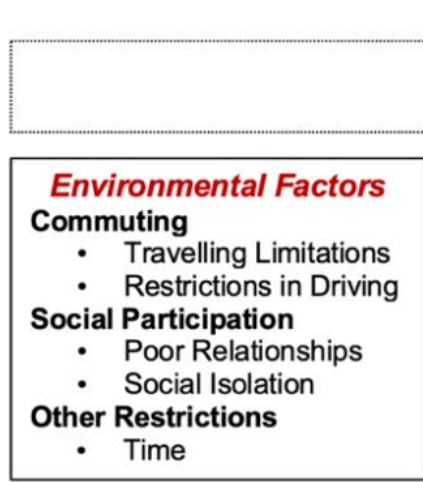

- Slow Reading

- Word Finding Difficulties

- Stuttering

- Swallowing Difficulties

Intensity of Involvement

- In all Stages

- Participant Recruitment

- Dissemination Events

Motivation

- Move Forward

- Joint Publication

- New Challenge

- Get in touch with research

- Make New Connections

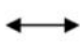

- Quiet Reading

- Translation Online

- Simplified Text

- Bullet Points

- Aphasia Friendly Format

Third-party support

- Communication Partners

- Family Members

- Between PWA

IMPACT
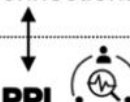

Communication via Email

nfluence and empower the Stroke community

Raise

Awareness

ack of education

Contribute to

dissemination

Promote Real

Life Priorities

Spread the

word via

support

organizations

Individualism

- Personal Experiences

- Tailor Made Research Priorities

- Physiotherapy

- Walk

- Quality of Life

Improve

Research

Outcome and

Impact

Review

878 influence the patient partners' stimulation and collaborative engagement within

879 the research team $[33,35]$. Under the Activity domain the acquired

880 communication difficulties are highlighted that restrict Involvement and personal

881 motivation and scope to participate in such research will boost level of

882 engagement. Similarity, under the Participation domain of the ICF framework, 
883 results were classified based on the Support needs proposed by participants.

884 These include constant technological, contextual and third part support to boost 885 communication effectiveness, paperwork management and meaningful 886 engagements. Under the Contextual factors, which encompasses both personal 887 and environmental factors affecting citizen-control PPI e.g., restrictions in 888 commuting and time in contrast with personal motivation, priorities, and the need 889 to express personal experiences for tailor-made collaboration processes.

890 The mapping of the PPI Impact as manifested by external variables and 891 patient-centred factors onto the ICF framework, revealed the interface between 892 stroke and aphasia with the overall impact of PPI on the research process. The 893 impact of $\mathrm{PPI}$, as discussed by participants, emphasises the immediate 894 dissemination of the results to the public, aphasia and stroke support 895 organizations, and the empowerment of stroke and aphasia communities. 896 Through this practice, patients will be informed about stroke and aphasia and 897 thus familiarize themselves with their condition, learn about living successfully 898 with stroke and aphasia in the chronic stage and self-educate on self899 management [47]. PWA also stressed that their involvement in PPI studies will 900 promote stroke and aphasia awareness to the public, both for the acute stage but 901 mostly for the 'life after stroke' phase where little or no evidence is available. 902 Consequently, stroke and aphasia PPI endorses the demands of people living 903 with stroke for better quality of treatment, rehabilitation, and community transition 904 training that will strengthen the research impact. This should be considered as 905 an important impact of PPI in stroke and aphasia research, albeit one that is in 906 some ways distant from the pre-established tasks of reviewing patient information 
907 leaflets, commenting on pre-established questionnaires or assisting with 908 recruitment processes.

909 This study underscores the value of the ICF as a conceptual tool in

910 qualitative analysis of participatory research methods. Of potential merit is

911 elaboration of the ICF in determining the personal factors and the provision of a

912 context-driven, process view of person-environment interaction within PPI

913 projects.

\section{Recommendations for PPI in stroke-aphasia studies}

915 The findings of this study suggest that involving PWA in all stages of PPI

916 research is challenging but possible. An inclusive PPI partnership model in stroke

917 and aphasia research reaching the citizen control level of Arnstein's ladder, will

918 encourage important research endeavors to avoid research 'waste', invigorate

919 the researcher-patient relationship dynamics, inform on the translation of the

920 research into everyday life, and empower communities of people with stroke and

921 aphasia. For these reasons, six recommendations for researchers to consider

922 before commencing the research process with PWA were identified. The

923 BEFORE recommendations are as follows:

924 1. Build rapport, offer information on PPI, and briefly explain research project 925 commitments prior to recruitment including timetabling and the issue of transport

926 2. Establish communication needs and barriers to participation based on detailed

927 information from the participant's case history and interview, to prepare for 928 research support accordingly

929 3. Foster a robust support system with communication partners, communication 930 facilitators or compensatory strategies 
931 4. Offer training courses on research vocabulary, design, and methodology using

932 accessible aphasia-friendly formats

933 5. Reinforce the use of tailored technological and contextual resources

934 6. Encourage potential PPI partners to participate in stroke and aphasia support groups to practice communication skills and social connectedness. This will later

936 put them in a better position to disseminate the research results.

937

938

939

940

941

942

943

944

945

946

947

948

949

950

951

952

953

954

955

\section{Results, Outcomes and Reflection on the PPI partner engagement}

AK the PPI partner contributed significantly to all stages of this study in several ways, including:

- She proposed one to one semi-structured interviews for information gathering.

- Assisted in participant recruitment.

- Pilot-tested the topic guide in practice interviews with the primary investigator MC.

- Suggested communication strategies to be used by the interviewer (MC) during the semi-structured interview meetings.

- Was present in the consensus meeting for the assemblage of the matrix and the finalization of the results (key themes).

- Contributed to the lay sections, the selection of the infographics and contributed to edits of the research paper.

While discussing and reflecting on the PPI collaboration as a team we report the engagement of the PPI partner in this study as most effective that influenced important aspects of the study as follows:

- the PPI partner had received training around research methods in previous studies during her $\mathrm{PhD}$ and because she was involved from 
956

957

958

959

960

961

962

963

964

965

966

967

968

969

970

971

972

973

974

975

976

977

978

979

980

the beginning of the study, she helped the rest of the team to shape the study from the start allowing her to contribute fully to the study's methodology.

- Having the right supportive context within a collaborative research team and a positive attitude AK assisted in the positive experience of her involvement on this study.

- The pre-existing relationships with AK provided a vital context for embedded PPI during the collaborative consensus meeting. Our aim of active PPI collaboration to co-produce knowledge worked well. However, there are a few limitations and challenges to mention. As AK reflected, during the consensus meeting, because of vast verbal and written material, AK got frequently fatigued, and we needed to take frequent breaks. The key challenge was to be proactive and prepare written materials in accessible formats and allow time for AK to identify ideas and respond at her own pace. Before the initiation of the consensus meeting, we had discussed whether we should have two separate meetings instead of one. Due to time restrictions, personal and professional obligations, and the COVID-19 lockdowns we decided to have one bigger session, which was eventually too tiring and demanding for AK.

\section{Limitations}

A limitation of this study is that none of the participants had previous experience with PPI projects and therefore the results cannot be generalized to all PWA and SSwoA to serve as research partners. Additionally, participants were active academics, former researchers, individuals who had experience in research methodology and could understand research practices and terminology. 
981 For this study participants presented with mild to moderate chronic aphasia and

982 were competent to independently participate using verbal communication. Since

983 the interviews were exclusively carried out using an online platform, opportunities

984 to use a variety of conversation support techniques to promote communication 985 access were limited. Instead, the interviewer often repeated words or phrases to 986 verify the interviewee's understanding, incorporated closed questions, used 987 simplified language, and clarified the subtle meanings of participant gestures or 988 facial expressions. Also, the number of participants might be considered as small. 989 With reference to saturation and pragmatic considerations of this study, the 990 number of selected participants is considered sufficient for the purpose of this 991 research. However, a single interview per participant qualitative design approach 992 was followed justifying the sample size [48]. Finally, because the interviews were 993 semi-structured, participants often strayed from the topic of discussion, and 994 directed the discussion to other topics, more personal and not related directly to 995 the proposed subject.

\section{Future recommendations}

997 PPI research on stroke and stroke-induced aphasia is limited and has not 998 been discussed at length in the literature. Our results revealed that the PPI 999 partner role is complex and difficult to define, especially when people with stroke 1000 present with persisting communication difficulties. This might explain why 1001 representatives of people with stroke and especially those with aphasia, tend to 1002 be involved primarily in a consultative role rather than co-researchers in related 1003 studies. Future research needs to focus on the ways PWA can be supported 1004 throughout the research process. It is vital to generate guidelines and 1005 frameworks as guiding principles for the PPI partnership model, which will 
1006 describe step by step, the methods and ways in which PWA can be facilitated to 1007 connect with the research process and prevent drop out. The BEFORE 1008 recommendations are a first step in this direction. Based on the findings of this

1009 study, the creation of such a conceptual framework will direct researchers on how

1010 to actively engage stroke survivors with aphasia in all stages of the PPI research

1011 process by monitoring its multidimensional nature and providing the necessary

1012 infrastructure to support it. In future research, the participants of this study will be

1013 re-interviewed after being involved as PPI partners in the PAOLI study, to explore

1014 change in their perspectives.

\section{Conclusion}

1016 In this study we have highlighted the invaluable role of PPI in stroke

1017 aphasia research and provided researchers practical recommendations to guide

1018 the involvement of people with chronic stroke, and especially those with aphasia,

1019 before the commencement of the research. All participants confirmed that they

1020 are willing to be involved in stroke and aphasia PPI studies but under specific

1021 conditions. This study generated novel findings about how PPI could be made

1022 accessible to PWA, presented the unique challenges, discussed the requirement

1023 for the development of robust support systems for a successful and sustainable

1024 PPI partnership model in stroke induced aphasia research and reflected the

1025 impact of meaningful contributions to research practices, end users and stroke 1026 and aphasia communities. It is hoped that this article will stimulate further 1027 discussion of the factors influencing the collaboration of people with stroke and aphasia in PPI projects.

1029

1030 
1032 Table 8. The GRIPP- 2 Short Form*

\begin{tabular}{|c|c|c|}
\hline Section and Topic & Item & $\begin{array}{l}\text { Reported on Page } \\
\text { Number }\end{array}$ \\
\hline 1 Aim & Report the aim of PPI in the study & 7 \\
\hline 2 Methods & $\begin{array}{l}\text { Provide a clear description of the } \\
\text { methods used for PPI in the study }\end{array}$ & $8-8,40-41$ \\
\hline $\begin{array}{l}3 \text { Study results } \\
\text { Outcomes }\end{array}$ & $\begin{array}{l}\text { Report the results of PPI in the } \\
\text { study }\end{array}$ & 40 \\
\hline $\begin{array}{l}4 \text { Discussion and } \\
\text { conclusions on } \\
\text { Outcomes }\end{array}$ & $\begin{array}{l}\text { Outcomes-Comment on the } \\
\text { extent to which PPI influenced the } \\
\text { study overall }\end{array}$ & $40-41$ \\
\hline $\begin{array}{l}5 \text { Reflections/critical } \\
\text { perspective }\end{array}$ & $\begin{array}{l}\text { Comment critically on the study, } \\
\text { reflecting on the things that went } \\
\text { well and those that did not }\end{array}$ & $40-41$ \\
\hline
\end{tabular}

1033 *PPI was secondary to this study, therefore information reported on the GRIPP-2 SF

1034 List of Abbreviations

1035 PPI: Patient and Public Involvement ; PWA: People with Aphasia; GRIPP:

1036 Guidance for Reporting Involvement of Patients and the Public; QOL: Quality of

1037 Life; PAOLI: People with Aphasia and Other Lay People Involvement; ICF:

1038 International Classification of Functioning and Disability Framework; COREs:

1039 Critical Outcomes of Research Engagement; MC: Marina Charalambous; IT:

1040 Ioanna Triantafyllidou; PP: Phivos Phylactou; AK: Alexia Kountouris; ASRS:

1041 Aphasia Severity Rating Scale; BDAE: Boston Diagnostic Aphasia Examination;

1042 SSwoA: Stroke Survivors without aphasia 
Supplementary Material

\section{Typical Consent form}

\section{Study Consent Form}

1054

Title of the Project: Development of the 'People with Aphasia and Other Laypeople Involvement (PAOLI) Framework', a comprehensive conceptual framework on PPI in aphasia research.

Name of Lead Researcher: Marina Charalambous PhD Researcher (University of Fribourg, Switzerland) Primary Supervisor: Jean-Marie ANNONI MD, PhD, Professor of Neurology (University of Fribourg, Switzerland) Secondary Supervisor: Maria Kambanaros, PhD, Professor in Speech Pathology (University of South Australia)

Please Initial Box

I confirm that I have read the invitation letter for the above study. I have had the opportunity to consider the information, ask questions and have had these answered satisfactorily.

I understand that my participation is voluntary and that I am free to withdraw at any time without giving any reason and without there being any negative consequences or my legal rights being affected. I understand that should I decide to withdraw then information already collected will be included in the data analysis in the study.

I understand that relevant sections of my data collected in the study may be looked at by authorised individuals from the University of Fribourg, the research team, and regulatory authorities as part of the research audit process. I give permission for these individuals to have access to these records.

$\square$ I understand that my name will not be identified during the Delphi survey or in the reports resulting from the research and my personal details will be kept strictly confidential.

I agree that non identifiable quotations and data may be used in this study and may be published in the research thesis, articles, on the study website and presented at conferences.

Completion: Please return scanned or electronically completed forms via email to: marina.charalambous@unifr.ch

Further information: Please do not hesitate to contact the lead researcher if you have any concerns or questions at: marina.charalambous@unifr.ch 


\section{Study Consent Form}

Title of the Project: Development of the "People with Aphasia and Other Layperson Involvement (PAOLI) Framework", a comprehensive conceptual framework for qualitative participatory approach in aphasia research.

Name of Lead Researcher: Marina Charalambous PhD Researcher (Unifr Switzerland) Primary Supervisor: Jean-Marie ANNONI MD, PhD, Professor of Neurology (Unifr Switzerland)

Secondary Supervisor: Maria Kambanaros, PhD, Professor in Speech Pathology (UniSa Australia)

I confirm that I have read

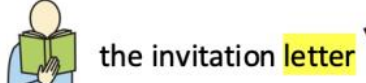

I have had the opportunity to consider the information and ask questions

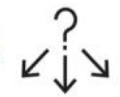

1110 I understand that my participation is voluntary

I understand that I am free to withdraw at any time without giving any reason 


\section{Acknowledgements}

1126 The authors wish to thank all people with chronic stroke and aphasia who

1127 participated in the study for their generosity and patience.

\section{Declaration of Conflict of interest}

1129 The authors declared no potential conflict of interest with respect to the research,

1130 authorship, and/or publication of this article.

\section{Authors Contribution}

1132 Marina Charalambous was the primary investigator/analyst who conceived the

1133 idea, collected the data, co-designed with Alexia Kountouris the study, analyzed

1134 the data and wrote the paper. Alexia Kountouris was the PPI partner- person with 1135 aphasia, who was involved in design, recruitment, data analysis and 1136 dissemination. Phivos Phylactou experimental psychologist experienced in

1137 thematic analysis contributed to the study's methodology, data analysis and

1138 interpretation and loanna Triantafyllidou was the second data analyst. Professor

1139 of Neurology Jean-Marie Annoni MD was the main reviewer of the manuscript

1140 and Professor of Speech Pathology Maria Kambanaros advised on the

1141 theoretical constructs, research method and reporting of the results in the

1142 manuscript. She oversaw the revising of the manuscript drafts and contributed

1143 significantly to the writing.

\section{Funding}

1145 This work was supported by the A.G. Leventis Foundation Doctorate Full

1146 Scholarship Grant, Geneva, Switzerland.

\section{Availability of Data and Material}

1148 Representative sample of transcript verbatims are presented in the article. The

1149 data generated during or analysed in the current study are not publicly available 
1150 due to ethical restrictions. All data queries and requests should be submitted to

1151 the corresponding author, Marina Charalambous PhD Researcher, for

1152 consideration.

\section{Ethics Approval}

1154 The study received ethics approval for conduct from the Cyprus Bioethics

1155 Committee (ЕЕВK/EП/2017/37).

1156

1157

1158

1159

1160

1161

1162

1163

1164

1165

1166

1167

1168

1169

1170

1171

1172

1173

1174

1175

1176

1177

1178

1179

1180

1181

1182

1183

1184

1185

1186

\section{Authors Details}

${ }^{1}$ Rehabilitation Sciences Department, Cyprus University of Technology, Cyprus ;marina.charalambous@cut.ac.cy,pp.phylactou@edu.cut.ac.cy, ia.triantafyllidou@edu.cut.ac.cy.2 Laboratory of Cognitive and Neurological Sciences, University of Fribourg, Switzerland; marina.charalambous@unifr.ch https://orcid.org/0000-0002-5310-3017,jean-marie.annoni@unifr.ch https://orcid.org/0000-0002-4751-0855. 3 "Solidarity Network Nicosia In Action" (NiclnAct), Multifunctional Foundation, Nicosia Municipality, Cyprus; Alexia.Kountouri@nicosiamunicipality.org.cy.4 Allied Health Unit, University of South Australia, Adelaide, South Australia;maria.kambanaros@unisa.edu.au https://orcid.org/0000-0002-5857-9460

\section{References}

1. Cruice M, Aujla S, Bannister S, Botting N, Boyle M, Charles N, Dhaliwal V, Grobler S, Hersh D, Marshall J, Morris S, Pritchard M, Scarth L, Talbot R, Dipper L. Creating a novel approach to discourse treatment through coproduction with people with aphasia and speech and language therapists. Aphasiology. 2021. doi: 10.1080/02687038.2021.1942775.

2. Hersh D, Israel M, Shiggins $C$. The ethics of patient and public involvement across the research process: towards partnership with people with aphasia. Aphasiology. 2021. doi: 10.1080/02687038.2021.1896870.

3. National Institute of Health. Research (NIHR). 2014. Patient and Public Involvement in Health and Social Care Research: A handbook for Researchers by Research Design Service London.: London: NIHR.

4. Thompson J, Bissell P, Cooper C, Armitage C, Barber R. Exploring the Impact of Patient and Public Involvement in a Cancer Research Setting. Qualitative Health Research. 2013;24(1):46-54.

5. Staniszewska S, Brett J, Mockford C, Barber R. The GRIPP checklist: strengthening the quality of patient and public involvement reporting in research. Int J Technol Assess Health Care. 2011;27(4):391-9. doi: $\underline{10.1017 / S 0266462311000481}$, PMID 22004782. 
1187

1188

1189

1190

1191

1192

1193

1194

1195

1196

1197

1198

1199

1200

1201

1202

1203

1204

1205

1206

1207

1208

1209

1210

1211

1212

1213

1214

1215

1216

1217

1218

1219

1220

1221

1222

1223

6. Staniszewska S, Brett J, Simera I, Seers K, Mockford C, Goodlad S, Altman DG, Moher D, Barber R, Denegri S, Entwistle A, Littlejohns P, Morris C, Suleman R, Thomas V, Tysall C. GRIPP2 reporting checklists: tools to improve reporting of patient and public involvement in research. BMJ. 2017;358:j3453. doi: $\underline{10.1136 / \mathrm{bmi} . j 3453}$, PMID $\underline{28768629}$.

7. O'Donnell M, Entwistle V. Consumer involvement in research projects: the activities of research funders. Health Policy. 2004;69(2):229-38. doi: $\underline{\text { 10.1016/j.healthpol.2003.12.011, PMID 15212869. }}$.

8. Mader LB, Harris T, Kläger S, Wilkinson IB, Hiemstra TF. Inverting the patient involvement paradigm: defining patient led research. Res Involv Engagem. 2018;4:21. doi: 10.1186/s40900-018-0104-4, PMID 30002875.

9. Swarbrick CM, Doors O, Scottish Dementia Working Group, Educate, Davis $\mathrm{K}$, Keady J. Visioning change: Co-producing a model of involvement and engagement in research (Innovative Practice). Dementia (London). 2019;18(7-8):3165-72. doi: 10.1177/1471301216674559, PMID 2 27753612.

10. Tembo D, Morrow E, Worswick L, Lennard D. Is Co-production Just a Pipe Dream for Applied Health Research Commissioning? An Exploratory Literature Review. Frontiers in Sociology. 2019;4. 10.3389/fsoc.2019.00050.

11. Arnstein SR. A ladder of citizen participation. J Am Inst Plann. 1969;35(4):216-24. doi: 10.1080/01944366908977225.

12. McKevitt $C$, Fudge $N$, Wolfe CDA. What is involvement in research and what does it achieve? Reflections on a pilot study of the personal costs of stroke. Health Expect. 2010;13(1):86-94. doi: 10.1111/j.1369-7625.2009.00573.x.

13. Harrison M, Palmer R. Exploring patient and public involvement in stroke research: a qualitative study. Disabil Rehabil. 2015;37(23):2174-83. doi: $\underline{10.3109 / 09638288.2014 .1001525 .}$.

14. Broomfield K, Craig C, Smith S, Jones G, Judge S, Sage K. Creativity in public involvement: supporting authentic collaboration and inclusive research with seldom heard voices. Res Involv Engagem. 2021;7(1):17. doi: 10.1186/s40900-021-00260-7, PMID 33731228.

15. Charalambous M, Kambanaros M, Annoni JM. Are people with aphasia (PWA) involved in the creation of quality of life and aphasia impact-related questionnaires? A scoping review. Brain Sci. 2020;10(10):688. doi:

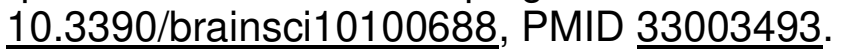

16. Pisano F, Marangolo P. Editorial: New perspectives and methodologies in the diagnosis and rehabilitation of aphasia. Brain Sci. 2021 [editorial];11(11):1508. doi: 10.3390/brainsci11111508, PMID $\underline{34827507}$. 
17. World Health Organization. The international classification of functioning, disability and health. Geneva: Author; 2001.

18. Tong A, Sainsbury P, Craig J. Consolidated criteria for reporting qualitative research (COREQ): a 32-item checklist for interviews and focus groups. Int J Qual Health Care. 2007;19(6):349-57. doi: 10.1093/intahc/mzm042, PMID 17872937.

19. Lawton M, Haddock G, Conroy P, Serrant L, Sage K. People with aphasia's perception of the therapeutic alliance in aphasia rehabilitation post stroke: a thematic analysis. Aphasiology. 2018;32(12):1397-417. doi: $\underline{10.1080 / 02687038.2018 .1441365 .}$.

20. Dillon EC, Tuzzio L, Madrid S, Olden H, Greenlee RT. Measuring the impact of patient-engaged research: how a methods workshop identified Critical Outcomes of Research Engagement. J Patient Cent Res Rev. 2017;4(4):23746. doi: $\underline{10.17294 / 2330-0698.1458}$, PMID $\underline{31413988}$.

21. Goodglass H, Kaplan E, Barresi B. Boston diagnostic aphasia examination. 3rd ed. Boston: Pearson; 2000. (p. BDAE-3).

22. El Hachioui H, Lingsma HF, Van de Sandt-Koenderman MW, Dippel DW, Koudstaal PJ, Visch-Brink EG. Long-term prognosis of aphasia after stroke. J Neurol Neurosurg Psychiatry. 2013;84(3):310-5. doi: 10.1136/innp-2012302596, PMID 23117494.

23. Kagan A, Kimelman M. Informed consent in aphasia research: myth or reality. Clin Aphasiol. 1995;23:65-75.

24. Rose TA, Worrall LE, Hickson LM, Hoffmann TC. Aphasia friendly written health information: content and design characteristics. Int J Speech Lang Pathol. 2011;13(4):335-47. doi: 10.3109/17549507.2011.560396, PMID $\underline{21682542 .}$.

25. Guba EG, Lincoln YS. Competing paradigms in qualitative research. In: Denzin NK, Lincoln YS, editors, Handbook of qualitative research. Thousand Oaks, CA: SAGE; 1994. p. 105-17.

26. Boyatzis RE. Transforming qualitative information: thematic analysis and code development. London: SAGE; 1998.

27. Braun V, Clarke V. Using thematic analysis in psychology. Qual Res Psychol. 2006;3(2):77-101. doi: 10.1191/1478088706qp063oa.

28. Nowell LS, Norris JM, White DE, Moules NJ. Thematic analysis: striving to meet the trustworthiness criteria. Int J Qual Methods. 2017;16(1). doi: $10.1177 / 1609406917733847$. 
29. Lawton M, Haddock G, Conroy P, Serrant L, Sage K. People with aphasia's perception of the therapeutic alliance in aphasia rehabilitation post stroke: a thematic analysis. Aphasiology. 2018;32(12):1397-1417.

30. Lloyd V, Gatherer A, Kalsy S. Conducting qualitative interview research with people with expressive language difficulties. Qual Health Res. 2006;16(10):1386-404. doi: 10.1177/1049732306293846, PMID 17079800.

31. Miqueu P, Williams A, Kairenius A, de Valeriola D. Patient involvement strategies to improve the quality of cancer care and research. Int $\mathrm{J}$ Integr Care. 2019;19(4):450. doi: 10.5334/iiic.s3450.

32. Isaksen J. "Well, You Are the One Who Decides": attempting shared decision making at the end of aphasia therapy'. Top Lang Disord. 2018;38(2):126-42. doi: $10.1097 /$ TLD. 0000000000000150.

33. Mann C, Chilcott S, Plumb K, Brooks E, Man MS. Reporting and appraising the context, process and impact of PPI on contributors, researchers and the trial during a randomised controlled trial - the 3-d study. Res Involv Engagem. 2018;4:15. doi: 10.1186/s40900-018-0098-y, PMID 29785283.

34. Towfighi A, Ovbiagele B, El Husseini N, Hackett ML, Jorge RE, Kissela BM, Mitchell PH, Skolarus LE, Whooley MA, Williams LS, American Heart Association Stroke Council; Council on Cardiovascular and Stroke Nursing; and Council on Quality of Care and Outcomes Research. Poststroke depression: A scientific statement for healthcare professionals from the American Heart Association/American Stroke Association. Stroke. 2017;48(2):e30-43. doi: 10.1161/STR.0000000000000113, PMID 27932603.

35. Schöttke H, Gerke L, Düsing R, Möllmann A. Post-stroke depression and functional impairments - A 3-year prospective study. Compr Psychiatry. 2020;99:152171. doi: 10.1016/i.comppsych.2020.152171.

36. Maddox L, Doran DR, Hubbart G 2017. Guide for researchers working with Patient and Public Involvement (PPI) Contributors. University of Oxford, University of Oxford's Nuffield Department of Primary Care Health Sciences. London: National Institute of Health Research (National Institute on Handicapped Research).

37. Stocks SJ, Giles SJ, Cheraghi-Sohi S, Campbell SM. Application of a tool for the evaluation of public and patient involvement in research. BMJ, (Open). 2015;5(3):e006390. doi: 10.1136/bmjopen-2014-006390, PMID 25770228.

38. Berg K, Isaksen J, Wallace SJ, Cruice M, Simmons-Mackie N, Worrall L. Establishing consensus on a definition of aphasia: an e-Delphi study of international aphasia researchers. Aphasiology. 2020:1-16. doi: $\underline{10.1080 / 02687038.2020 .1852003}$. 
39. Kambanaros M. Evaluating personal stroke narratives from bilingual GreekEnglish immigrants with aphasia. Folia Phoniatr Logop. 2019;71(2-3):101-15. doi: $\underline{10.1159 / 000493126}$.

40. Taubner $\mathrm{H}$, Hallén $\mathrm{M}$, Wengelin $\AA$. Still the same? - self-identity dilemmas when living with post-stroke aphasia in a digitalised society. Aphasiology. 2020;34(3):300-18.

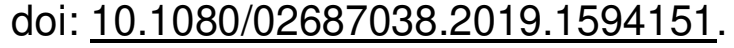

41. Jayes M, Moulam L, Meredith S, Whittle H, Lynch Y, Goldbart J, Judge S, Webb E, Meads D, Hemsley B, Murray J. Making Public Involvement in Research More Inclusive of People With Complex Speech and Motor Disorders: The I-ASC Project. Qual Health Res. 2021;31(7):1260-74. doi: $\underline{10.1177 / 1049732321994791}$, PMID $\underline{3645331}$.

42. Menger F, Morris J, Salis C. Internet use in aphasia: A case study viewed through the international classification of functioning, disability, and health. Top Lang Disord. 2017;37(1):6-24. doi: 10.1097/TLD.0000000000000110.

43. Simmons-Mackie N, Raymer A, Cherney LR. Communication partner training in aphasia: an updated systematic review. Arch Phys Med Rehabil. 2016;97(12):2202-2221.e8. doi: $\quad$ 10.1016/j.apmr.2016.03.023, $\quad$ PMID $\underline{27117383}$.

44. Souchon NM, Krüger E, Eccles R, Pillay BS. Perspectives of working-age adults with aphasia regarding social participation. Afr J Disabil. 2020;9:713. doi: 10.4102/ajod.v9i0.713, PMID 33392061.

45. Caute A, Woolf C. Using voice recognition software to improve communicative writing and social participation in an individual with severe acquired dysgraphia: an experimental single-case therapy study. Aphasiology. 2016;30(2-3):245-68. doi: $\underline{10.1080 / 02687038.2015}$

46. Duggan $\mathrm{C}$, Albright $\mathrm{K}$, Lequerica A. Using the ICF to code and analyse women's disability narratives. Disability and Rehabilitation. 2008;30(1213):978-990.

47. Rhoda A, Groenewald R, Altigani R, Jones F 2021. Self-management and stroke. 10.1007/978-3-030-69736-5_5.

48. Vasileiou K, Barnett J, Thorpe S, Young T. Characterising and justifying sample size sufficiency in interview-based studies: systematic analysis of qualitative health research over a 15-year period. BMC Med Res Methodol. 2018;18(1):148. doi: 10.1186/s12874-018-0594-7, PMID 30463515. 